chamber. They open posteriorly at the basal portion of the vertical tube referred to above, which communicates between the epibranchial chamber and the exhalant chamber.

This vertical passage is bound anteriorly by the investment of the posterior surface of the adductor muscle and posteriorly by a septum $(S S)$, which is continuous with the interbranchial septum and which separates the inhalant part of the branchial chamber from the exhalant one. This septum corresponds to the intersiphonal septum of other Lamellibranchiata. This vertical channel in its upper region passes insensibly into the exhalant chamber. On the other hand, its lower or basal portion has a number of ridges and protuberanees which form a composite plug, which on contraction of the animal closes off this channel and consequently the exhalant chamber from the interbranchial chamber and the interlamellar cavities of the gills.

The composite plug referred to above is partly formed of a fairly big protuberance on the lower posterior region of the investment of the adductor muscle (Figs. $A$ and $D$ ). This protuberance marks the spot where the axes of the gills become free from the body wall of the animal. As these get loose from the investment of the adductor muscle their edges are thickened and are directed first forwards and outwards and then backwards and inwards (Fig. $A, X$ ), where they end at the base of the intersiphonal septum (SS). In this fashion the free edge of each axis takes the form of a well-developed notch with greatly thickened lips which mark the opening communicating the interbranchial cavity with the vertical tube and consequently the exhalant chamber. At the base of the siphonal septum $(S S)$ there is a thickened part which corresponds to the protuberance facing it on the investment of the adductor muscle.

When the animal contracts, the posterior region of the thickened mantle edge, which is very highly muscular $(A, P)$, coils downwards and forwards and comes to press on the siphonal septum, which in its turn presses on the posterior surface of the adductor muscle. In this fashion the thickened region of the septum, together with the protuberance of the investment of the adductor muscle, are applied close to one another, blocking the major part of the cavity of the tube. At the same time, the thickened edges of the free part of the axes are also applied together, blocking the side parts of this communicating tube.

Theexhalant chamber, which is continuousposteriorly with the vertical tube, is in the form of a well-defined bag extending on the dorsal surface of the animal. It ends blindly at the extreme anterior end of the animal $(A)$. It opens to the outside by the well-defined exhalant opening $(E X)$, and its only communication with the other chambers of the mantle is through the communicating vertical channel (cf. text Fig. 3 of Yonge $^{4}$ ).

The exhalant chamber is provided with a number of well-defined muscle bands (oblique and vertical), running between the floor of the chamber in the region of the adductor muscle and the roof of the chamber in front and behind the exhalant opening. The part these muscles play in the process of pumping out the water from this chamber to the outside is very obvious. The retractor muscles of the foot also seem to have a very important part in this process. A great number of their elements run between the foot $\left(F^{\prime}\right)$ and the thickened mantle edge in the region of the exhalant opening $(B)$.
The combined action of the muscles of the thickened mantle edge especially at the posterior end, of the adductor muscle, of the vertical and oblique muscles of the exhalant chamber and partly that of the retractor muscles, brings great pressure upon the contents of the exhalant chamber, and hence the remarkable spouting of the water through the exhalant opening. The insertion of the retractor muscle into the mantle edge in the region of the exhalant chamber seems also to provide support to the roof of the chamber round the opening and prevents rupture through the great pressure from the inside when contraction takes place. In the contracted condition the composite plug referred to above seems to be quite efficient in stopping any communication between the exhalant chamber and the interbranchial and the interlamellar portions of the mantle cavity. The difference of pressure in these two sets of chambers when the animal is contracting must be very great, and the importance of the plug in such a condition is quite obvious.

When the animal retracts, the capacity of the exhalant chamber increases greatly, the vertical tube increases in width, and water coming originally from the branchial chamber is sucked upwards into the exhalant chamber from the interbranchial chamber and the interlamellar cavities of the gills.

The alternate contraction and retraction of the muscles of the animal in the way described above causes, at least at intervals, a strong current of water to pass through the gills. The food-collecting value of this process cannot be overlooked. Experimental data pertaining to the pressure in the different chambers and the rate of flow of the water through the animal are fortheoming.

${ }^{1}$ Mansour, K., Proc. Eguptian Acad. Sci., 1 (1946) (in the press). 2 Vaillant, L., Ann. Sei. nat. Zool,, (5), 4 (1865).

${ }^{3}$ Lacaze-Duthiers, H. de, Arch. Zool. Exp. Gén., (3), 10 (1902).

- Yonge, C. M., Great Barrier Reef Expedition Sci. Rep., 1, No. 11 (1936).

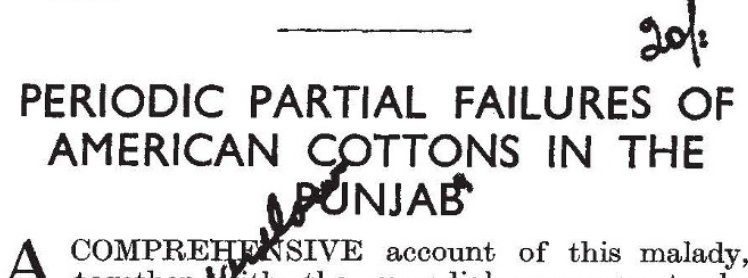
A together fith the remedial measures to be

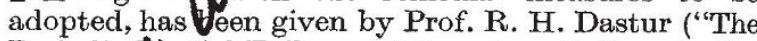
Periodic Wrtial Failures of American Cottons in the Punjalk "Their Causes and Remedies". Sci. Monogroph. No. 2, India . Central Cotton Committee, Bothbay, 1945). The failure in question is of the nature of a physiological disease, popularly known as 'tirak', the symptoms of which include the premature cracking of bolls with immature seeds and poor quality of lint. On light sandy loams the leaves become discoloured at the onset of the reproductive phase, the characteristic yellow and red colours being followed by premature leaf fall. A study of the cotton crop in the Punjab in all its phases of growth led to the general view that where tirak is evident the vegetative and reproductive phases are physio. logically unbalanced: the detailed investigation of this hypothesis has been productive of many interesting results of both practical and scientific interest.

In the first place, tirak is now regarded as a com prehensive term for several abnormal physiological developments induced in American cottons (Gossypium hirsutum) under quite different soil conditions. 
Two particular soil types are specified as being liable under certain conditions to give rise to tirak : these are light sandy loams deficient in nitrogen, and soils which contain free sodium salts or sodium clay in the subsoil. Different types of physiological disorder are induced under the two sets of conditions, but the name tirak is still retained to cover both. The more evident symptoms which develop on the first soil type have already been indicated; but in addition it has been found that in the leaves of affected plants there is an abnormal accumulation of starch in the cells of the mesophyll. This starch is not removed during the night, as in normal leaves, but continues to accumulate until in extreme cases the chloroplasts become ruptured. An abnormal accumulation of a tannin-like substance is also present in the cells, its presence being antecedent to the development of the external symptoms of tirak. The relation of these abnormal developments to nitrogen deficiency has been established by appropriate experimentation. The observation that, on light sandy loams, tirak cannot be attributed to nitrogen deficiency alone led to investigations of the water economy of the plant. Water deficiency during the reproductive phase was also found to be a factor in the situation. Thus where water deficiency is important, as in soils with subsoil salinity, affected plants show a pronounced drooping of the leaves; these leaves also become dark-coloured and dull, they lose their fresh green shining appearance and are prematurely shed. In this type of tirak the yellowing seen in nitrogendeficient plants is not present; there is likewise no evidence of the accumulation of starch or tannin, but certain protoplasmic abnormalities are evident. Both types of tirak-affected plants are characterized by a low potassium content in leaves and carpels, depressed synthesis of proteins, and decreased oil formation in seods.

A careful consideration of all the relevant biochemical data has led to the conclusion that the low potassium content is the starting-point of the internal disorders in tirak plants. The disorders associated with this deficiency develop in different ways in plants growing on the two soil types : in the light sandy loams the uptake of potassium is low because of the shortage of nitrogen ; on saline soils physiological drought interferes with the normal uptake of minerals. Thus Prof. Dastur concludes (p. 71) : "The common symptom, viz., immaturity of seed, therefore, developed in plants on both soil types though the symptoms exhibited by the leaves of tirak-affected plants on the two soil types were found to differ". Such a finding gives some idea of the difficulties inherent in the investigation of a crop failure which is due to physiological disorders.

Broadly speaking, the field aspect of the problem has been diagnosed along the following lines. When Punjab-American cottons are sown early in May, the combination of light soil, long days and regular water supply makes for strong vegetative growth. Flowering begins about the last week in August. It is a curious and important fact that any change in the date of sowing is not accompanied by a similar shift in the onset of flowering; that is, all sowings tend to come into bearing within a rather narrow period. Moreover, flowering tends to occur in a flush and thus imposes a heavy demand on the supplies of nitrogen and other minerals. This is particularly so in the case of the strongly vegetative plants which result from the early May sowings. In point of fact, a large number of flowers do not come into fruition as fully developed bolls. This tends to be accentuated in soils which are deficient in nitrogen or which suffer from physiological drought, with the concomitant develop, ment of the two types of failure described as tirak, These and many other interesting aspects of the problem are fully described and discussed.

A substantial part of the report deals with the remedial measures to be adapted to different soil types. To quote from the report (p. 137): "The application of nitrogen to light sandy soils prevented the development of tirak symptoms caused by nitrogen starvation and the application of extra water at the fruiting stage prevented the development of physiological drought on soils with saline subsoils. Both these remedies proved specific for the two soil types and naturally they must be applied at the right place.

"The importance of the June-sowings as a preventive measure against tirak was its gen'eral applic. ability. It was found efficacious on all soil types as it put the crop in equilibrium with its surroundings. . . The plants were able to carry on their normal functions with less nitrogen and less water [than the May-sowings] and the deficiency of these substances did not develop. The plants were also better able to stand the adverse weather conditions at the fruiting stage and thus general intensification and spread of tirak were greatly lessened. The internal economy of the plant greatly improved and the plant produced less of sticks and more of fruits. . . This simple measure of deforring sowings by about three to four weeks has been found to result in great profits to cotton growers and many of them have already benefited."

Prof. Dastur and his collaborators, and the Indian Central Cotton Committee which sponsored and financed the work, are to be congratulated on the successful outcome of this long and intricate investi: gation.

\section{TRANSMISSION OF FINGER-PRINTS BY RADIO}

THE transmission pictures and of written or printed materif frover line and radio telegraphic circuits is an proverement of long standing; but in recent years. Chormous advances have been made in the tec pique of radio transmission and reception in the field, resulting in very marked improvement in no quality and detail of the reproduced pictures, excellent examples of which are frequently to be seen in the daily. Press. The successful transmission to a distance of reproductions of human finger-prints, obviously demands an unusually high quality in this. technique, and a study of the problems involved in this. application has been the object of tests conducted during the past year between Great Britain and Australia.

These tests are described in an interesting pamphlet. entitled "Radio Transmission of Finger Prints", by. Superintendent F. R. Cherrill, officer-in-charge of the. Finger Print Branch, New Scotland Yard*. A foreword to this document refers to an article entitled "The Description and Use of the Pores in the Skin of the Hands and Feet", published in the Philosophical Transactions of the Royal Society in 1684 by. Dr. Nehemiah Grew, who was at one time secretary.

* Radio Transmission of Finger Prints. By Supt. F. R. Cherrill. Pp. 12. (Commissioner of Police of the Metropolis, New Scotland Yard, London, S.W.1, 1946.) 